\title{
The Integration of Subject Specific Skills and Small Group Teaching into Year 1 of Degree Programmes: A Study Skills Programme, a School-Wide Learning and Teaching Initiative
}

\author{
Violetta Naughton, Patrick J. Naughton \\ School of Biomedical Sciences, Ulster University, Coleraine, Northern Ireland \\ Email: v.naughton@ulster.ac.uk, pj.naughton@ulster.ac.uk
}

How to cite this paper: Naughton, V. and Naughton, P.J. (2017) The Integration of Subject Specific Skills and Small Group Teaching into Year 1 of Degree Programmes: A Study Skills Programme, a School-Wide Learning and Teaching Initiative. Open Journal of Social Sciences, 5, 300-320.

https://doi.org/10.4236/jss.2017.57019

Received: June 30, 2017

Accepted: July 18, 2017

Published: July 21, 2017

Copyright $\odot 2017$ by authors and Scientific Research Publishing Inc. This work is licensed under the Creative Commons Attribution International License (CC BY 4.0).

http://creativecommons.org/licenses/by/4.0/

\begin{abstract}
This paper presents and discusses a student-focussed, small group learning and teaching, and school-wide initiative designed for first year undergraduate students in support of their transition into higher education. The details of the underlying pedagogic strategy, as well as the organisation (small group teaching environment), the content of applied learning and teaching approaches (including assignment and assessment), and the outcomes of the initiative evaluation (including required human resources) based on data collected from five consecutive academic years are presented. This paper aims to serve as an example of a pedagogic approach that facilitates student transition into Higher Education aimed at practitioners, especially those involved in delivery and/or those who are engaged or responsible for undergraduate curricula development. The findings are discussed in terms of implications for curricular changes to support students' engagement at this early stage of their university career.
\end{abstract}

\section{Keywords}

Student-Centred Learning, Student Engagement, First Year Undergraduate, Transition

\section{Introduction}

First-year undergraduate students face challenging times during their first few months at university owing to the rapid and radical lifestyle changes as well as new academic demands. Many students experience problems adapting to their new environment, which, in turn and in agreement with Maslow's hierarchy of 
needs [1], affects their wellbeing and sometimes their health and more often than not reduces their learning ability; consequently they fall short of their academic expectations. The collective pressure of arriving into a new social environment and academic demands results in students leaving their courses within a few weeks of registration, which in turn negatively affects the host institution. In the UK the importance of supporting students during the transition period i.e. within first few months of the registration onto their chosen undergraduate degree programme, has been on the agenda of individual Higher Education Institutions (HEI's) for over a decade now e.g. University of Wolverhampton [2], University of Derby [3], University of Abertay [4], University of Glasgow [5] as well as the focus of nation-wide initiatives e.g. Student Transition and Retention Project, funded by the Higher Education Funding Council for England [HEFCE] and Department for Higher and further Education, Training and Employment under the Fund for the Development of teaching and Learning, Northern Ireland. The aforementioned project has led to a number of initiatives aimed primarily at improving student retention e.g. via extended induction for at risk students at Edinburgh Napier University [6], a series of lunchtime workshops for mature students at University of Sheffield [7] or non-subject specific study skills sessions offered to first year undergraduates at Ulster University [8], to name but a few.

At Ulster (formally University of Ulster and currently Ulster University) these initiatives led to the development of skills tutorials to support first year undergraduate students during their transition into university [9] and involved tutor-led tutorials focusing on non-subject specific material which were offered to undergraduate students in semester 1 of their programmes of study. These sessions were organised outside of the curricula of the courses studied by students. However, after the first year of delivery it was realised that both the students as well as the academic staff would benefit from a more organised approach in terms of both physical and human resources to support these sessions. Such an institutional approach in support of first year student transition into university has since been recognised and recommended by teaching practitioners across the world. For example, the importance of first year curriculum design has been highlighted e.g. Kift et al. [10] indicated that first year curricula that includes pedagogic strategies (allowing for peer-engagement, engagement with staff, early identification of students' needs and prompt provision of both academic and non-academic support to students) have a direct impact on first year students experience. Moreover, current examples include work by Sharp and colleagues [11] who have presented a holistic institutional model of a course designed specifically aiming to support first year undergraduate students during the transition period.

In our school, the structure and the content of the aforementioned skills tutorials have, since been revised to include bioscience related material. The incorporation of subject specific content and academic skills (e.g. scientific report writing, academic poster preparation and presentation and exercises in refer- 
encing scientific literature) into the curricula of the degree programmes in the format of regular tutorial sessions has allowed for both early support of students' future careers, the early development of transferable, academic skills and the development of the cohorts i.e. programme-specific identities [9] [12].

Incorporation of the skills tutorials into the curricula of the degree programmes has also facilitated the allocation of both physical and human resources in support of tutorial delivery. This consequently allowed for a choice of teaching and assessment strategies that provided not only academic benefits to learners but has also allowed direct support of students' social needs at the time of the transition to the university.

This paper presents the details of the pedagogic strategy, as well as the organisation, the content, including assignments and assessment methods that have been developed and applied into the first semester of the first year of a number of undergraduate courses in our School. The paper is structured as follows:

2. Learning and Teaching Strategy, including the following aspects

2.1. Background to the First Year Curricula and the Selection of a Pedagogic Strategy to Support Students' Transition

2.2. SSP Organisation of Formal Learning Groups vs. Teaching Plan (including the topics of weekly activities)

2.3. Organisation of the Formal Learning Groups vs. Group Assignment

2.4. Evaluation of the SSP

3. Retrospective Overview of the SSP

3.1. Students and Staff Involved in the SSP

3.2. Students' Participation in the Formal Learning Groups

3.3. The Outcomes of SSP Evaluations by Students

4. Discussion (of the pedagogic approach used and the outcomes of SSP evaluation)

5. Conclusion

This paper aims to serve as an example of a pedagogic approach that facilitates student transition into university. It is aimed at practitioners, especially those involved in the delivery of first year curricula but also those who are engaged or responsible for undergraduate curricula development.

\section{Learning and Teaching Strategy}

\subsection{Background to the First Year Curricula and the Selection of a Pedagogic Strategy to Support Students' Transition}

Every year, a high number of first year undergraduate students from different educational backgrounds enrol on a number of undergraduate programmes in the School of Biomedical Sciences at Ulster. The entry requirements to these programmes range from 240 UCAS tariff scores (a points system used by the Universities and Colleges Admission Services in UK to report educational achievements for entry into higher education) and a minimum of one science subject (predominantly Home Economics) to 340 UCAS tariff scores with a 
minimum of two science subjects (including Biology and/or Chemistry or Physics). The curricula of the individual programmes are designed according to the programmes learning objectives, however in semester 1 of the first year the majority of first year students are required to study three common modules (units of delivery) in Introductory chemistry, Human physiology and Biostatistics. These are taught in large class settings of $>150+$ students. The skills tutorials were incorporated into the curricula of the first semester mandatory biostatistics modules of seven undergraduate courses including BSc Hons Biology, BSc Hons Biomedical Sciences (three distinctive programmes), BSc Hons Pharmacology, BSc Hons Human Nutrition, BSc Hons Food and Nutrition, BSc Hons Dietetics. The inclusion of the skills tutorial sessions into the undergraduate programmes curricula meant that the context of the sessions was translated, into the learning objectives (LOs) specific for each degree programme involved, which in turn was appropriately assessed (according to the standards of the higher education provider and national quality standards; for info see UK Quality Code for Higher Education). Inherently, the learning objectives have been focused on the transferable skills (see Table 1 for a listing of the specific skills sets included in the relevant LOs). However, the LOs were not specific to a given subject of study; and thus may be applicable to other first year curricula elsewhere.

The formulation of the relevant LOs, was in line with the main goal of the tu-

Table 1. A list of skills incorporated into the curricula of first year undergraduate programmes including skills accompanied by the relevant learning outcomes as well as the skills that are not assessed. However, both materials and time have been made available within the curriculum to support students to develop given skills.

Skills taught, practiced and assessed and thus associated with appropriate learning outcomes*

Distinguishing between ideas, opinions and judgment in own writing

Expressing key themes in a predictable and standard written format

Presenting correctly formatted scientific communications

Using the Internet to supplement lecture and laboratory material

Writing effectively and with precision

Working with and meeting obligations to others i.e., cooperating with others in contributing to a group achieving a defined goal

Skills taught and practiced

Standards and criteria in higher education

Learning styles

Deep approaches to learning

Learning from lectures, practicals and tutorials

Self- and peer-assessment

Task management

Time organisation; revisions and examination tactics

*Note that the skills presented above are not in the form required for presentation of LOs in any formal document; for information on how to write LOs you may wish to refer to Bloom's Taxonomy of Educational Objectives (Bloom et al., 1994) 
torials i.e. to provide support to first year undergraduate students during the transition period. These LO's underpinned the content of the session. Formal (tutor-led) cooperative learning groups were established to complete specific coursework assignment tasks which were determined to be the most appropriate pedagogic strategy to achieve both the requirements of the LOs and the main goal of the tutorial sessions. The application of the chosen pedagogic strategy as well as the consistency of the delivery and the assessment within-year (i.e. between different programmes and between groups within each programme), and between academic years' was ensured through the leadership of an appointed, 'Study Skills Co-ordinator' in the School i.e. designated cross-programme academic leadership of staff concentrating on student-centred learning and a teaching philosophy focused on positive student experiences.

An overview of the weekly contents and format of the student transition tutorials referred to since its formal introduction into the undergraduate curricula as the Study Skills Programme (SSP) is presented in Table 2. A key element of the SSP delivery were regular sessions in small learning and teaching environment, aiming to provide appropriate setting for regular interactions between students themselves and between students and experienced academic staff. To encourage students' engagement each session was underpinned by the work planned for each consecutive session such as prior reading or completion of specific exercises prior to attending class.

\subsection{SSP Organisation of Formal Learning Groups vs. Teaching Plan}

Following registration and prior to the beginning of semester 1 of each academic year, the first year students were divided into course/degree programme specific cohorts for both subject specific lectures and practical library sessions e.g. biology vs. dietetics vs. biomedical sciences etc. Also, in the case of the lectures, these were delivered by academic staff directly involved in the development and delivery of the given programmes either in their specific academic roles (e.g. the course directors) or invited speakers representing relevant professional bodies. Such an approach supported initial development of "professional" identities, previously not well focused on first year students who were taught together in large common modules.

Following allocation into the degree specific cohorts, students were divided into small teaching/tutorial groups (7 - 16 students) observing the degree programme of study to further foster cohort identity and to provide opportunities for social interactions with their peers. Each tutorial group was assigned an academic member of staff (called a "group tutor") who was chosen from the academic subject related to the degree programme. The tutor was responsible for the SSP content delivery and individual students' progress over the entire semester. The tutors were inducted and mentored by the SSP Co-ordinator in all aspects of SPP prior to the start of each academic year to assure consistency of SSP delivery, including the structure, format of SSP assignments and guidance 
Table 2. The content and format of the Study Skills programme integrated into the first year undergraduate curricula of seven undergraduate BSc Hons degree programmes; the contents is presented in the order of its delivery.

Contents
Introduction to the module and programme of study (aims, contents, etc.).
Allocation to the groups for tutorial sessions and particulars of the tutorial
sessions' timetable.
IT and Library Induction (organised centrally by the University for each
course).
Ice breaker aiming to get to know peers and staff.
Introduction to studying at university/exercises on how university differs/
may differ from school (work in groups); followed up by discussion on
particulars of university learning, teaching and assessment. Info and
discussion on roles of studies advisors, module coordinators, course
directors, students' representatives. Study skills self-assessment exercise
followed by Q\&A.
Studying at university (cont.) -including exercise on "economics of failure"
followed by the group discussion; outcomes of Time Management exercise
and group discussion; outcomes of students assessment of their predominant
learning styles followed by discussion on how to develop appropriate learning
strategies; Discussion on teamworking and taskwork; introduction to peer-
and self-assessment followed by Q\&A.
Topics of assignment given out; allocation into posters teams (formal
learning groups), rules and organisation of group work, followed by Q\&A.

Searching for scientific information; originality of own work vs. plagiarism; referencing (why and how).

"How do I read" exercise followed by group discussion; exercises related to technical side of referencing and originality of own writing followed by discussion and Q\&A. How to prepare scientific poster: rationale and technical side; practical exercises on poster preparatory steps and designs, discussion and Q\&A.

Training in use of library catalogues and scientific databases.

Scientific writing (principles, rules, examples).

Exercises related to scientific writing; formative comments on draft work (posters and individual written assignments) followed by Q\&A; Skills self-re-assessment exercise.

Training in a use of selected referencing software followed be student independent work in the library.

Your course and its module components vs. future careers. Placement-what it is and its role for future careers. Professional bodies and/or learned societies.

Discussion on careers, placement options and relevant professional topics; Working on posters (finishing touches). Revision of rules of peer- and selfassessment of individual contributions to group work in light of the minutes from poster team meeting, discussion and Q\&A.

Posters (presentation) session; peer-assessment of presented posters; selection of the best poster; reflection on the group work.

Preparing for examinations; formats of examination papers, revision of consequences of failure, extenuating circumstances and appeals; etc.

Feedback on the posters; feedback from the tutor and a summary of peerfeedback; comparing and contrasting feedback obtained with theoretical information on how to use feedback.
Format

Lecture

Practical session

Tutorial session

Tutorial session

Tutorial session

Practical session

Tutorial session

Practical session

Lecture

Tutorial session

Tutorial session

Lecture

Tutorial session 
on marking criteria for assessment as well as the level of support which should be provided to students within and between the groups. During SSP delivery, additional support was made available to those tutors who lacked experience in small group teaching or needed clarification on any SSP related matters. The SSP handbook was developed containing the pedagogic aim of each session, a brief description of suggested activities and details of assignments and assessment and it was provided to each academic tutor prior to the beginning of teaching in each academic year.

Support materials were provided to students in a student handbook including theoretical information and practical exercises related to the SSP content. This included detailed descriptions of all assignments as well as an assessment guide with relevant examples and sample marking criteria for discussion and then agreement with the students. Notably, the materials prepared for students were supplied with examples and information relevant to the content of the course/ degree programme on which students were registered. Also, all materials for the students were in the form of hard copies (booklets) so as not to cause anxiety to those students who were unfamiliar with the university virtual learning environment (VLE), normally used to share other learning/support materials.

SSP teaching sessions e.g. tutorials, lectures and interactive library training were run on a weekly basis. Student progression and attendance at SSP sessions was monitored on a weekly basis over the entire semester allowing for early identification of those students who may have experienced difficulties with acclimatization to the university.

\subsection{Organisation of the Formal Learning Groups vs. Group Assignment}

In week three of the semester, i.e. when all initial introductions to their new environment, peers and staff and students and the University expectations were completed, students were allocated into formal learning groups. These formal learning groups were established within the tutorials groups to work on one of the coursework assignments i.e. scientific poster (details on this assignment below).

To form the formal learning groups, the students within each tutorial group were allocated by their tutor to smaller poster teams consisting of a minimum of three to maximum of six members. The students' allocation to the poster teams were made randomly, as even in week 3 of the semester staff were not in possession of any parameters to rationalise blocking e.g. level of academic attainment; also, unequal gender balance on some degree programmes i.e. where programmes mainly recruit female students, hence no blocking by gender. However, students were not permitted to change their poster team to be teamed up with e.g. with "their mates" from their previous home area or school. Notably, the membership of each poster group was maintained unchanged for the entire duration of the group work on the poster aiming to encourage students to learn to prevent and to resolve interpersonal issues, if such occurred. 


\section{Poster Assignment}

Following the allocation to the poster teams, students were presented with the subject specific topics as well as the set of rules governing both the teamwork as well as the subsequent assessment of both the individual contribution to teamwork and the final product of their team work i.e. a scientific poster. The rules of team work were related to the assessment of both individual contribution to the team-working effort and the assessment of the final product of the teamwork; in brief those rules stipulated the following: i) team members were required to cooperate with other members of the team when planning all group activities such as organising meetings, collecting information, generating and interpreting results, technical work on the poster etc., ii) teams were required to provide evidence of individual contribution to team work and whole group progress on the poster via a) formal record of individual and group activities in a written form and b) self- and peer-assessment of contribution to team activities and work.

The written record i.e. minutes from the poster team meetings had to be prepared on a regular basis (preferably weekly) and it had to clearly reflect the group progression on the task as well as showing the individual contribution of each member to the team effort. Each written record had to be approved (signed) by all members of the poster team and submitted to the SSP tutor for formative comments. It was also a requirement that the roles of the group leader and the record keeper be rotated so that each member of the poster team was provided with an opportunity to lead the group and work on the record of group activities. The students were supplied with working examples and templates of minutes of meetings as well as a self-and peer-assessment form. The self-and peer-assessment was based on the marking criteria provided to students by the SSP tutor (see Table 3), which were explained and discussed with students during a tutorial session. Notably, the students were advised that their self-and peer-assessment must be substantiated/corroborated by the minutes from the poster team meetings and vice versa. Additionally, students had been provided with the relevant examples and the theoretical rationale of the rules governing the group work; tutorial time was allocated to discuss the rules with students allowing for learners' understanding and the integration of related theoretical concepts.

Table 3. Aspects of self-and peer-assessment of performance and participation to the team activity.

Aspects that you need to consider; note that you need to support each aspect with evidence via previously submitted minutes from poster team meetings

Was he/she regularly at group meetings, punctual \& co-operative?

Did he/she contribute ideas and suggestions for the project?

How well did he/she carried out the tasks assigned by the group?

Did he/she accept a fair share of the work?

How would you rate his/her overall contribution to the project? 
The content of weekly SSP sessions (for details please refer to Table 1) were designed in support of the students' progress on their assignments via development and/or fostering of the relevant skills sets. Furthermore, the 'exemplar' marking criteria for the teamwork and the poster were discussed with students and then translated with students' involvement into final marking criteria applied at the time of the assessment by academic staff. To assure consistency between groups, the tutors were always required to provide the agreed (with students) marking criteria to SSP coordinator for the moderation prior to returning the final version of the marking criteria to students.

A formal presentation of the posters was scheduled during a SSP tutorial session towards the end of the semester simulating a typical poster session at a scientific meeting. The overall aim of this scheduled session was to allow students to present their scientific poster to their peers and tutor for discussion. Additionally, the tutors were advised to provide students with the formative assessment of the draft posters during one of the tutorial sessions prior to the formal poster presentation session. Also, at the formal presentation of the posters, the students were presented with an opportunity to note the strengths and weaknesses of the posters authored by other teams (peer-feedback for improvement); this exercise was guided with a simple form (see Table 4) supported by verbal explanation of each aspect of peer-assessment provided by the tutor at the start of the session. Notably, and aiming to avoid personalisation of the critique, tutors have been advised to collect the resulting peer-assessment forms and to summarise the outcomes of peer-assessment prior to returning peers feedback to the authors of the posters.

\subsection{Evaluation of the SSP}

A qualitative approach was used to assess students' opinion on the SSP. During the initial stage i.e. within first two cycles (two academic years) of the SSP introduction into the undergraduate curricula, the annual evaluation of the SPP was based on students' opinions collected via a simple free response, anonymous evaluation questionnaire that included open-end questions i.e.: 1) What were the

Table 4. Characteristics of the students on the Study Skills Programme considered here i.e. over the reported period of five academic years.

\begin{tabular}{|c|c|c|c|c|c|c|}
\hline Academic Year (AY) & 2008/09 & $2009 / 10$ & $2010 / 11$ & 2011/12 & $2012 / 13$ & $\begin{array}{l}\text { Total over the } \\
\text { reported period }\end{array}$ \\
\hline Number of programmes and science disciplines (indicated in brackets) & $8(4)$ & $7(3)$ & $7(3)$ & $7(3)$ & $7(3)$ & $8(4)^{*}$ \\
\hline Number of new entrants into all programmes that were included in the SSP & 133 & 175 & 115 & 141 & 152 & 716 \\
\hline \multicolumn{7}{|l|}{ Entry qualifications of new entrants included in the SSP } \\
\hline A-levels [\%] & 76 & 74 & 63 & 70 & 76 & 72 \\
\hline Irish Leaving Certificate [\%] & 14 & 10 & 14 & 9 & 7 & 11 \\
\hline Other e.g. Higher National Diploma [\%] & 11 & 15 & 23 & 21 & 17 & 17 \\
\hline
\end{tabular}

${ }^{*}$ This includes all programmes/disciplines taking SSP over reported period of five consecutive academic years. 
three best things about Study Skills Programme? 2) What were the three things about Study Skills Programme you would most likely to see improved? Following this two-year SSP specific evaluation, and from academic year 2010/2011 the students' opinions relevant to the SSP were extracted from the university-wide learning and teaching evaluation system that collects students' opinions on each unit (module) of teaching at the end of each semester of each academic year.

\section{Retrospective Overview of the SSP}

\subsection{Students and Staff Involved in the SSP}

Over the period of five academic years, a total of 716 first year new entrants to collectively eight undergraduate BSc Hons programmes have participated in the SSP. The programmes included Biomedical Sciences (three programmes), Pharmacology, Food and Nutrition, Human Nutrition and Dietetics but by 2009/10 the Pharmacology programme had been withdrawn while the Biology programme was incorporated into the SSP (more details in Table 4).

Out of 716 students, 518 students on the SSP were admitted onto their programmes based on their A-levels results. Additionally, 76 students taking the SSP were admitted based on their results from Irish Leaving Certificate (ILC) examination, which broadly equate to the British/Northern Irish A-levels. Therefore, the number of students on the SSP who came directly from the secondary type education equalled 594 i.e. $83 \%$ of all students on the SSP (see Table 5 for more details on the new entrants qualifications).

The overall number of students recruited each year to the programmes varied (with the lowest number of 117 and the highest number of 175; see Table 5 for details) and thus the number of the tutorial groups and required number of group tutors to assure the SSP delivery varied from 10 to 12 per year; correspondingly, the total number of staff required to deliver the SSP each year varied between 17 to 19 per year (see Table 5 for details). The turnover rate of staff from the home institution (i.e. after exclusion of invited speakers) involved in the SSP delivery measured as the number of those who left SSP after the cycle (academic year) by the total number of staff at the beginning of the cycle (and presented

Table 5. Staff involved in the Study Skills Programme delivery considered here i.e. over the reported period of five academic years.

\begin{tabular}{cccccc}
\hline Academic Year (AY) & $2008 / 09$ & $2009 / 10$ & $2010 / 11$ & $2011 / 12$ & $2012 / 13$ \\
\hline Overall & 17 & 20 & 18 & 18 & 19 \\
Group tutors & 10 & 12 & 10 & 10 & 11 \\
$\begin{array}{c}\text { Other (lectures delivery, library training, } \\
\text { programme coordination)* }\end{array}$ & 7 & 8 & 8 & 8 & 8 \\
Staff turnover rate & & & & 27 \\
All staff [\%] & 21 & 29 & 20 & 27 & 36 \\
Group tutors [\%] & 30 & 33 & 30 & 30 & 27 \\
\hline
\end{tabular}

${ }^{\star}$ This includes the university staff but not invited speakers from outside of the home institution. 
Table 6. Contribution to the teamworking activity within the SSP vs. the proportions of those who left their programmes, within first year of their course i.e. early leavers. The indicators of early leavers at local (Northern Ireland) and National (UK) level are also presented for comparison.

\begin{tabular}{cccccc}
\hline Academic Year (AY) & $2008 / 09$ & $2009 / 10$ & $2010 / 11$ & $2011 / 12$ & $2012 / 13$ \\
\hline $\begin{array}{c}\text { Percentage of students who have not } \\
\text { contributed to the group work }\end{array}$ & 0.9 & 1.2 & 4.2 & 2.1 & 1.3 \\
$\begin{array}{c}\text { Early Leavers [\%] from those included in } \\
\text { the SSP }\end{array}$ & 5.7 & 6.4 & 5.2 & 2.1 & 4.2 \\
$\begin{array}{c}\text { Reference data: Early Leavers [\%] } \\
\text { Northern Ireland }\end{array}$ & 9.0 & 8.2 & 5.7 & 6.0 & 6.0 \\
UK* & 6.5 & 7.2 & 6.3 & 5.7 & 5.7 \\
\hline
\end{tabular}

*From Summary-Higher Education Statistics Agency, UK, Performance Indicators https://www.hesa.ac.uk/data-and-analysis/performance-indicators/summary.

as \%) varied from $20 \%$ to $29 \%$ per year, while the turnover rate of group tutors varied from $30 \%$ to $36 \%$ depending on the year (see Table 6 for annual turnover data).

\subsection{Students' Participation in the Formal Learning Groups}

Each academic year attendance at the weekly SSP sessions was characterised as very good (>85\%) up to week $7-8$ of the semester but then attendance decreased slightly in weeks 9 - 10 (>60\%) with attendance recovering again to $100 \%$ towards the end of semester and around the time of formal poster assessment.

Overall, the participation of students in the formal learning group was excellent but in each academic year, a very small number of students did not contribute to the activities of the formal learning groups (see Table 6 for details). On two occasions there were clear cases of exclusion of individuals by the poster group members; those two cases were identified early and acted upon by the SSP tutors concerned. The remaining cases of those who did not contribute to the activities of the formal teaching groups were students who were absent from their studies (for more than a week) due to personal extenuating circumstances; notably, the students affected by the extenuating circumstances were offered substitute assignments, which took into account their individual needs as well as the interests and progress on work of the teams to which affected individuals were allocated.

In terms of the reported period (five academic years), in four of the academic years the number of students who did not participate in the formal learning groups was lower than the number of those students who left their programme within first year i.e. "early leavers" (see Table 6 for details).

\subsection{The Outcomes of SSP Evaluations by Students}

The SSP specific evaluation involved collectively 215 students, including 96 and 119 i.e. $72 \%$ and $68 \%$ of the students taking the SSP in academic year 2008/09 and 2009/10, respectively. The evaluation was based on the open-end questions 
and thus allowed the students complete freedom in terms of their comments on the programme. Yet when asked about "Three best aspects of the SSP' $50 \%$ of all responding students listed the SSP aspects directly related to the formal learning groups that is "team-working" as the best aspects of the SSP. Second listed best aspect of the SSP have been "getting to know other students on their course" (49\% of respondents), while the third aspect have been the SSP learning environment i.e. "learning/teaching in small groups" (36\% respondents) and finally "poster preparation and presentation" (31\% respondents). Other SSP aspects mentioned by students included subject specific lectures (10\% respondents), scientific writing training (5\% respondents), referencing training (5\% respondents). The aspects listed by individual respondents included e.g. introduction into university life/assessments/expectations, learning styles and how to revise efficiently, interactive/activity based type of learning and teaching, learning styles assessment and training on how to revise efficiently, peer- and self- assessment exercise etc. The qualitative results of the SSP evaluation can be further exemplified by students' comments:

"Teamwork was cool"

"Group work was enjoyable"

"Working in teams on the poster was great"

"Working in a team was best"

"Working with other members of class on assignments"

"The skills aspect of the module was very helpful. It gave me a better understanding of how the University's policies work and how I can go about tackling any problems that I may have in relation to the University. Also, working on a poster allowed me to get to know other students on my course."

Last but not least, when asked "What would you like to see improved with this module" the respondents suggested that SSP would benefit from more tasks that require teamworking ( $28 \%$ respondents) or noted that there is no need for changes (26\% respondents); other individual suggestions included technical suggestions e.g.:

"decrease number andl or length of classes" (22\% respondents), "provide more or longer classes" (18\%), "re-schedule classes for different day andlor time of a day" (19\% respondents), "provide different classroom" (8\% respondents), "make Library training longer" or "make Library training shorter" (collectively 5\% respondents); did not give any answer (38\% respondents).

By far the largest number of respondents did not give any answer to this question (38\% respondents).

To note, the SSP evaluation questionnaires were collected anonymously and completed by the students on a voluntary basis and hence did not allow for the collection of demographic data.

\section{Discussion}

During the course of any higher education programme, students undergo a number of educational and social transitions of which the most obvious and ar- 
guably most significant transition occurs when they enter a new institution such as university or college of further education [13]-[18]. Other more obvious transitions occur when students are re-entering the institution after a longer period of work-based learning (after a placement) or after a period of leave of absence from their home institution and their study programme [19] [20]. Alternatively, individuals may undergo educational and/or social transitions when transferring from one programme to another (within or outside the institution) or simply be faced with unfamiliar modes of learning and teaching and changing expectations over the time of their study programme [20]. Anecdotally, some educational practitioners claim that historically most students have been able to deal with these transitions with little support from staff/institutions, while nowadays many students are rarely able to manage through their degree unaided. Regardless of whether we agree or disagree with such claims, one must acknowledge that our current students are likely subjected to a fast paced live-style associated with social-media and the 24/7 culture, that many young and inexperienced adults find difficult to manage. An example of the detrimental effects of modern life style on students wellbeing can be drawn from the results of a report by the Centre for Collegiate Mental Health at Penn State University [21] indicating that up to 50\% of all college students calling on counselling services experienced general and social anxiety. Furthermore, the report states that "The number of students treated by counselling centres grew at more than $5 \mathrm{x}$ the rate of institutional enrolment and the number of attended appointments grew at more than $7 \mathrm{x}$ the pace of institutional enrolment." ([21], p. 7). Aside from the possible detrimental effects of modern life-style on students' wellbeing, the transition to an institution of higher education has been shown to be associated with other negative emotions such as a homesickness [22] and loneliness [23]. It is therefore not surprising that such negative psychological effects combined with previously reported academic challenges e.g. increased workload and/or higher academic expectations [24] affect students' learning abilities and consequently their early academic performance. More recent qualitative research by McMillian [25] has examined the extent to which the transition to the new institution is perceived as an emotional event and has made an attempt to identify academic and nonacademic variables affecting students well-being during the transition period. Based on the results of his study McMillian reports that his results are in agreement with previously published literature and he states that "Students" greatest emotional fear appeared to be that of alienation-being an outsider without friends. Their most positive emotion was focused on the development of professional identity [25]. Notably, McMillian is referring to Heathcote and Taylor's [26] theory of emotional stages accompanying students during their academic career based on which, he postulates that students need to journey through those stages "However, they need to be accompanied on that journey by someone who has travelled that path already. This experienced traveler can help them identify where they are on the journey." The results of the SSP evaluation from our School strongly support McMillian's observations. The survey of students' opi- 
nions on the SSP conducted over two academic years has shown that in both years the most important aspects of the SSP for the majority of responding students was facilitation of group interactions with other students. These group interactions were facilitated by a specific learning and teaching strategy i.e. utilization of small formal (included into curricula) learning groups.

Small learning groups are also acknowledged to initiate cooperative learning [27]. According to Panitz [28] the learning that is based on the cooperative learning groups can be defined as: “(...) a set of processes, which help people interact together in order to accomplish a specific goal (...) which is usually content specific" and further he elaborates that "cooperation is a structure of interaction designed to facilitate the accomplishment of a specific end product or goal through people working together in groups (...) in the cooperative model the teacher maintains complete control” and further he argues, “(...) cooperative learning represents the best means to approach mastery of foundational knowledge (...)" [28]. The results of a number of, more recent meta-analyses on the effectiveness of the cooperative learning indicate that this pedagogic strategy affords efficient learning of theoretical concepts, internalisation of transferable and professional skills, while learners deem their learning experiences as positive and more engaging [29] [30]. Hence, the formal cooperative learning groups with their pre-determined, tutor-facilitated structure and organisation would appear to be most suitable for the novice undergraduate students, especially at the initial stage of their university education. Furthermore, it should be noted that the formal learning groups can encompass all participatory learning and teaching methods, such as group discussions, teaching others and practice by doing, all of which suit novice undergraduate students, most of whom arrive from the secondary school system. Indeed, the majority of the students considered in this report had arrived directly from the secondary school system and thus our chosen pedagogic approach appeared to provide the vast majority of the newly registered entrants with the most familiar learning environment. This approach was deemed to be the most suitable to engage these students with what was otherwise an unfamiliar university learning with unfamiliar teaching and assessment methods [31], as well as a new social environment. Indeed, the literature indicates that participatory teaching methods and interactions with classmates initiate and strengthen acclimatisation of new entrants to the university community; for example, it has been previously shown that social learning communities play an important part in successful transition into tertiary education [32] [33].

The main characteristic of a formal cooperative learning group is that it relates to a very small number of students i.e. preferably up to five students involved in a group work for the model to be successful. Therefore, the learning and teaching of the students within relatively small tutorial cohorts of up to 16 students/group described in this paper was directly associated with the further allocation of students into smaller poster teams so as to allow for all the benefits of cooperation in learning. Other characteristics of the formal cooperative 
learning groups have been previously summarised by McInnerney and Roberts [34] as follows "1) Positive interdependence (...) all for one and one for all (...); 2) face-to-face promoting interaction: some work within the group is done individually, but the group does most work interactively; 3 ) individual and group accountability: the group as a whole is accountable for achieving the group's goal and the individual within the group is accountable for contributing to the group goal; 4) interpersonal and small group skills: teaching students to engage in taskwork and teamwork, simultaneously; 5) group processing: the group assesses its goals and how well it is progressing". The listed characteristics clearly dictated the structure and organisation of the formal learning groups in our SSP, however further reflection on these characteristics, specifically "some work within the group is done individually, but the group does most work interactively" indicates the need for a task/goal for the group work that will facilitate both individual contributions, however also assuring a certain level of interdependence when working on the assigned task.

In general, a task assigned to the group can be categorized based on type of group work it instigates i.e.: a task/assignment that instigates simple workload share and the one that more likely instigates interdependent type of work [12]. Simple workload share tasks/assignments incite group members to do individual bits of the overall work so as to complete the assignment; in other words, with the outcomes of the individual work simply contributing to the total/final product (e.g. on-line discussions, participation in interactive lectures). In most cases, such tasks/assignments allow easy identification and, if applicable, the assessment of the individuals' work contributions [12]. Furthermore, the tasks/ assignments instigating simple workload share may allow for group membership and/or the frequency of the individual contributions to be rather flexible, or even allowing members to leave/change the learning group in case of e.g. unharmonious interactions or even the absence of interactions within the group. The tasks that instigate simple workload share can be therefore classified as "low risk", tasks/assignments. If such "low risk" tasks/assignments are assigned to a group small enough to allow each group member to contribute to the group work face-to-face and the group work is regulated/monitored by a tutor, then this type of group work may result in interactive work expected from formal cooperative learning groups. However, the work involved although, easy to manage by learners and tutors, is often questioned by some students because of the very nature of "low risk" tasks. The most frequent argument used against "low risk" tasks by the university students themselves relate to work efficiency i.e. the work on task could be completed quicker/more efficiently without a real need to work in groups! This clearly indicates that even "low risk tasks/assignments must include a need for at a least a minimal requirement for interdependent work". The examples of the students' views on this subject include comments extracted from e.g. https://www.thestudentroom.co.uk/ i.e.:

"Group work only makes sense if the project is so big that one person cannot do all the work (think Engineering, Software, Research collaborations, Theatre, 
Film productions etc.). For such big projects it makes sense to assign specific roles and responsibilities to each member of the group, based on skill-set. If someone is not doing their job it will be very obvious and that person can be held to account for it."

"I agree that probably universities want to make students work effectively in groups on a small scale, and I agree that this could be done. I think both universities and students generally fail at it because it is (most of the time) not taught or made explicit - neither at school nor at university. (Probably because most teachers or lecturers do not understand group work either.) Doing it badly is just a waste of time for everyone, especially if you can do better on your own."

However, it has to be noted that as opposed to "low risk" tasks, the more complex work tasks, typical for normal working environment require specific knowledge and/or skills from individual members of a group. Such tasks are normally based on close interactions between the group members. Therefore, such tasks/assignments in a university setting may cause difficulties to both learners and tutors, especially if the assessment of individual contributions to the group effort is required. Also, the likelihood of within-group conflicts in relation to highly interdependent work is higher, in particular in the case of heterogeneous and newly established groups [35] [36]. Therefore, the more complex tasks/ assignments can be categorized as "high risk" tasks. In fact "high risk" tasks/ assignments may not be suitable for novice undergraduate students even if such strategy is underpinned by a well-planned systematic structure, including details of assessment, as well as regular tutor monitoring/support. Furthermore, the type of the assessment chosen for assessing the formal learning group work, in terms of both individual contributions and the overall group outcome may help or hinder e.g. due to competitiveness, the integration of the group integration an inevitably the progress on the assigned task. Another example from https://www.thestudentroom.co.uk/ supports this:

"The idea of group projects at university is great in theory, but in reality it often doesn't work and results in one or two people having a nervous break down while everyone else clears off down the pub... I would much rather be judged on my own efforts as it seems fairer than either being dragged down or benefiting from others work."

The examples above, although unorthodox, clearly support our notion that for the formal learning groups to be effective, the structure and the organisation of the groups and the assigned tasks need to be well planned beforehand taking the learners' knowledge and skills into consideration, as it was previously observed with regards to working in teams in a workplace [37]. Therefore, group participants as well as their assigned tutors must be equipped with the knowledge and practical teamworking skills, as appropriate. The outcomes of the Study Skills Programme as presented in this paper would indirectly support the notion that offering "low risk" tasks to novice undergraduate students can be effective, if appropriate training and support is provided to tutors and the students themselves. 
We believe our approach to transition is similar to the $3 \mathrm{C}$ model proposed by Sharp and co-workers [11]. In their study, the importance of cohesion, coherence and connectedness was clear. In our approach the importance of providing clear information [38] [39] in the form of a hard copy handbook/workbook was clear. This handbook provided week-by-week guidance to students including information and literature to support the lecture sessions but also the small group tutorials; all aiming and allowing novice students to understand the rationale, the process and academic practice. Importantly the small group learning environment during regularly scheduled tutorials allowed individual tutors, where time allowed, to integrate formative tasks that students could complete in groups of two or three students. The ratio of one staff member to $14-16$ students for the entire semester provided the opportunity for connectedness where students could more easily relate to the staff member during the tutorials [40]. This process also allowed for the connectedness of staff particularly when it came to sharing best practice and also the moderation of inter-group assessments. An important aspect of the SPP is that it was responsive-the connectedness of staff meant that new and or revised assessments could be easily introduced, which would not have been possible within a defined modular structure. This made the process responsive but yet clearly aligned [41] to the programme on which the students were registered. Tinto [42] and others have identified that high-quality academic experience with academic support, paired with social involvement and peer support are crucial if you wish to retain your students. Our SSP model has clearly met these needs in terms of academic tutors leading small group tutorials where students are introduced to each other in a non-competitive environment and clearly falls within the 'senses of success' model framework as proposed by Lizzio [43].

One of the key founding principles behind the SSP programme was that it would not only improve transition and the retention of our students but also that it would instil key elements of scientific training in our students hence the selection of Short (Scientific) Report writing, the application of Scientific referencing styles and the Preparation and Presentation of a (Scientific) Poster. These key elements combined with the opportunity for students to get feedback on drafts of their work prior to submission were key, and would not be possible in large class sizes normally experienced in year one of our programmes. Throughout this process and the years when the SSP ran throughout the School the test was how to balance positive enforcement with academic achievement in the context of group work. Sharp et al. [11] put forward the view that it's about the journey and not necessarily the stops in between. The pursuit of "low risk" but valid scientific tasks/exercises instils in students the fundamental scientific skills that will be called upon throughout their degree programme and into their eventual scientific career. The advantage of this approach is that at the same time it meets the needs of students in terms of cohesion, coherence and connectedness allows a balance to be met. In agreement with Krause [44] this ties in with a University's vision to develop a community and a culture that increases the con- 
fidence and engagement by our students (co-committed self-regulation of learning behaviour). Krause [44] and indeed De Angelo et al. [45] argue that interventions to improve student transition are more successful when they are matched to the needs of the student population.

\section{Conclusion}

In conclusion, the study skills programme in the School of Biomedical Science was a success. Therefore, the decision was taken to create bespoke "skills" modules as part of the periodic review/revalidation of programmes process in 2013/ 2014. This led to the development of new individual modules/units in year 1 of the Biology, Biomedical Science and Food and Nutrition programmes. The small group tutoring and assessment elements, which were so crucial to the success of the Study Skills programme, were retained within these new modules. This case study describes a second generation approach to transition emphasising the importance of academic led small group teaching and bespoke subject specific elements in any approach to aiding students in their transition to higher education. We commend this approach to colleagues in the wider STEM area and those in the Humanities and Business areas who wish to aid their students in their transition to Higher Education.

\section{References}

[1] Maslow, A.H. (1943) A Theory of Human Motivation. Psychological Review, 50, 370-396.

[2] Halstead, A. (2007) Institutional Retention Strategies. In: Cook, A., and Rushton, B.S., Eds., Student Transition and Retention (STAR), University of Ulster, Coleraine, 14-15.

[3] Barber, P. and Edwards, S. (2007) An Initial Transition Strategy: The Difficult Transition from School to University. In: Cook, A., and Rushton, B.S., Eds., Student Transition and Retention (STAR), University of Ulster, Coleraine, 23-27.

[4] Staal, J. (2007) Personalisation of Retention Support and the Use of MIS Systems and Data. In: Cook, A. and Rushton, B.S., Eds., Student Transition and Retention (STAR), University of Ulster, Coleraine, 28-30.

[5] Cheng, M, Barnes, G.P., Edwards, C., Corduneanu, R. and Koukou, M. (2015) Transition Skills and Strategies; Report: Transition Models and How Students Experience Change September 2015. Report 2015. The Quality Assurance Agency for Higher Education, Gloucester. www.enhancementthemes.ac.uk

[6] Huxham, M. (2006) Extended Induction Tutorials for 'at Risk' Students. In: Cook, A., and Rushton, B.S., Eds., Student Transition and Retention (STAR), University of Ulster, Coleraine, 37-50.

[7] Linehan, K. (2006) Bread and Butter: A Lunchtime Workshop to Develop Mature Students' Fundamental Learning Skills. In: Cook, A. and Rushton, B.S., Eds., Student Transition and Retention (STAR), University of Ulster, Coleraine, 51-60.

[8] Cook, A. (2006) A Survey of Current Practice of Induction in the Biosciences. In: Cook, A. and Rushton, B.S., Eds., Student Transition and Retention (STAR), University of Ulster, Coleraine, 11-25.

[9] Cook, A. and Naughton, V. (2006) Biomedical Sciences Tutorials. In: Cook, A. and 
Rushton, B.S., Eds., Student Transition and Retention (STAR), University of Ulster, Coleraine, 13-36.

[10] Kift, S., Nelson, K. and Clarke, J. (2010) Transition Pedagogy: A Third Generation Approach to Fye-A Case Study of Policy and Practice for the Higher Education Sector. The International Journal of the First Year in Higher Education, 1, 1-20.

[11] Sharp, S., O’Rourke, J.A., Lane, J.M. and Hays, A. (2014) Cohesion, Coherence and Connectedness: The 3C Model for Enabling-Course Design to Support Student Transition to University. Proceedings of International Conference of the Australian Association for Research in Education. Brisbane, 30 November-4 December 2014, 14-28.

[12] Naughton, V., O'Connor, J. and Cook, A. (2007) Peer Assessment in Collaborative Learning for First Year Undergraduates in the School of Biomedical Sciences. In: Cook, A. and Rushton, B.S., Eds., Student Transition and Retention (STAR), University of Ulster, Coleraine, 63-64.

[13] Tinto, V. (1987) Leaving College: Rethinking the Causes and Cures of Student Attrition. University of Chicago Press, Chicago.

[14] Hillman, K. (2005) The First Year Experience: The Transition from Secondary School to University and TAFE in Australia, Longitudinal Surveys of Australian Youth, Research Report 40. Australian Council for Educational Research and the Australian Government Department of Education, Science and Training, Melbourne.

[15] Harvey, L., Drew, S. and Smith, M. (2006) The First-Year Experience: A Review of Literature for the Higher Education Academy. The Higher Education Academy, London.

[16] Clark, J. and Hall, L. (2010) Exploring Transition: The Experiences of Students at Newcastle University in Their First Year. Newcastle University, Newcastle upon Tyne.

[17] Briggs, A.R.J., Clark, J. and Hall, I. (2012) Building Bridges: Understanding Student Transition to University. Quality in Higher Education, London.

[18] Coertjens, L., Brahm, T., Trautwein, C. and Lindblom-Ylänne, S. (2017) Students' Transition into Higher Education from an International Perspective. Higher Education, 73, 357-369.

[19] Auburn, T. (2007) Identity and Placement Learning: Student Accounts of the Transition Back to University Following a Placement Year. Studies in Higher Education, 32, 117-133. https://doi.org/10.1080/03075070601099515

[20] Bridges, W. (2011) Managing Transitions: Making the Most of Change. 3rd Edition, Nicholas Brealey Publishing, London, UK/Boston, USA.

[21] Center for Collegiate Mental Health (2015) The 2015 Annual Report. Penn State University, 501 Student Health Center, State College.

[22] Burt, C.D. (1993) Concentration and Academic Ability Following Transition to University: An Investigation of the Effects of Homesickness. Journal of Environmental Psychology, 13, 333-342. https://doi.org/10.1016/S0272-4944(05)80255-5

[23] Pargetter, R. (2000) Transition: From a School Perspective. Journal of Institutional Research, 9, 14-21.

[24] Lowe, H. and Cook, A. (2003) Mind the Gap: Are Students Prepared for Higher Education? Journal of Further and Higher Education, 27, 53-76. https://doi.org/10.1080/03098770305629

[25] McMillan, W. (2013) Transition to University: The Role Played by Emotion. European Journal of Dental Education, 17, 169-176. https://doi.org/10.1111/eje.12026 
[26] Heathcote, E.A. and Taylor, P.G. (2007) The Potential Contribution of Change Management Literature to Understand and Support Student Transitions. Proceedings of Higher Education Research and Development Society of Australasia 2007 Enhancing Higher Education, Theory and Scholarship, 8-11 July 2007, Adelide, 233.

[27] Davis, B.G. (1993) Collaborative Learning: Group Work and Study Teams. In: Tools for Teaching, Jossey-Bass, San Francisco, 147-152, 156.

[28] Panitz, T. (1996) A Definition of Collaborative vs. Cooperative Learning.

[29] Romero, C.C. (2009) Cooperative Learning Instruction and Science Achievement for Secondary and Early Post-Secondary Students: A Systematic Review. Colorado State University, Fort Collins. http://search.proquest.com/docview/304862896

[30] Kyndt, E., Raes, E., Lismont, B., Timmers, F., Cascallar, E. and Dochy, F. (2013) A Meta-Analysis of the Effects of Face-to-Face Cooperative Learning. Do Recent Studies Falsify or Verify Earlier Findings? Educational Research Review, 10, 133-149. https://doi.org/10.1016/j.edurev.2013.02.002

[31] Wilson, K.L., Murphy, K.A., Pearson, A.G., Wallace, B.M., Reher, V.G. and Buys, N. (2016) Understanding the Early Transition Needs of Diverse Commencing University Students in a Health Faculty: Informing Effective Intervention Practices. Studies in Higher Education, 41, 1023-1040. https://doi.org/10.1080/03075079.2014.966070

[32] Wilcox, P., Winn, S. and Fyvie-Gauld, M. (2005) It Was Nothing to Do with the University, It Was Just the People: The Role of Social Support in the First-Year Experience of Higher Education. Studies in Higher Education, 30, 707-722. https://doi.org/10.1080/03075070500340036

[33] Roccini, L.M. (2011) The Impact of Learning Communities on First Year Students' Growth and Development in College. Research in Higher Education, 52, 178-193. https://doi.org/10.1007/s11162-010-9190-3

[34] McInnerney, J.M. and Roberts, T.S. (2004) Collaborative or Cooperative Learning. Online Collaborative Learning. Theory and Practice, 203-214. https://doi.org/10.4018/978-1-59140-174-2.ch009

[35] Jackson, S.E. (1992) Consequences of Group Composition for the Interpersonal Dynamics of Strategic Issue Processing. In: Dutton, J., Huff, A. and Shrivastava, P., Eds., Advances in Strategic Management, JAI Press, Greenwich, 345-382.

[36] Hansen, Z., Owan, H. and Pan, J. (2015) The Impact of Group Diversity on Class Performance: Evidence from College Classrooms. Education Economics, 23, 238258. https://doi.org/10.1080/09645292.2013.813908

[37] Jackson, S.E., Joshi, A. and Erhardt, N.L. (2003) Recent Research on Team and Organizational Diversity: SWOT Analysis and Implications. Journal of Management, 29, 801-830. https://doi.org/10.1016/S0149-2063(03)00080-1

[38] Long, M., Ferrier, F. and Heagney, M. (2006) Stay, Play or Give It Away? Students Continuing, Changing or Leaving University Study in First Year. Centre for the Economics of Education and Training (CEET), Monash University, Melbourne.

[39] Keane, E. (2011) Dependence-Deconstruction: Widening Participation and Traditional-Entry Students Transitioning from School to Higher Education in Ireland. Teaching in Higher Education, 16, 707-718. https://doi.org/10.1080/13562517.2011.570437

[40] Krause, K.L. (2007) Beyond Classroom Walls: Students' Out-of-Class Peer Experiences and Implications for Teaching and Learning. Nagoya Journal of Higher Education, 7, 301-318.

[41] Cullity, M. (2005) Alternative Entry Programmes to University for Mature Age Students: Programme Characteristics that Encourage or Inhibit Mature Student 
Participation. The University of Melbourne, Melbourne.

[42] Tinto, V. (1998) Colleges as Communities: Taking Research on Student Persistence Seriously. The Review of Higher Education, 21, 167-177.

[43] Lizzio, A. (2006) Designing an Orientation and Transition Strategy for Commencing Students. A Conceptual Summary of Research and Practice. First Year Experience Project. Griffith University, Brisbane.

[44] Krause, K.L. (2005) Understanding and Promoting Student Engagement in University Learning Communities. A keynote Address 'Engaged, Inert or Otherwise Occupied? Deconstructing the 21st Century Undergraduate Student' at the James Cook University Symposium 2005, Sharing Scholarship in Learning and Teaching: Engaging Students. James Cook University, Townsville/Cairns.

[45] DeAngelo, L., Franke, R., Hurtado, S., Pryor, J.H. and Tran, S. (2011) Completing College: Assessing Graduation Rates at Four-Year Institutions. Higher Education Research Institute, Los Angeles.

Submit or recommend next manuscript to SCIRP and we will provide best service for you:

Accepting pre-submission inquiries through Email, Facebook, LinkedIn, Twitter, etc. A wide selection of journals (inclusive of 9 subjects, more than 200 journals)

Providing 24-hour high-quality service

User-friendly online submission system

Fair and swift peer-review system

Efficient typesetting and proofreading procedure

Display of the result of downloads and visits, as well as the number of cited articles

Maximum dissemination of your research work

Submit your manuscript at: http://papersubmission.scirp.org/

Or contact jss@scirp.org 